Japutra $^{\mathrm{a}}$, A., Ekinci ${ }^{\mathrm{b}}$, Y. and Simkin ${ }^{\mathrm{c}}$, L. (2017-Accepted). The role of ideal self-congruence and brand attachment in consumers' negative behaviour: Compulsive buying and external trashtalking. European Journal of Marketing.

${ }^{\mathrm{a} U n i v e r s i t y ~ o f ~ W e s t e r n ~ A u s t r a l i a, ~}{ }^{\mathrm{b}}$ University of Portsmouth, ${ }^{\mathrm{c}}$ Coventry University 


\title{
The role of ideal self-congruence and brand attachment in consumers' negative behaviour:
}

\author{
Compulsive buying and external trash-talking
}

\begin{abstract}
Purpose - The purpose of this study is to investigate the role of ideal self-congruence in instigating two types of negative consumer behaviours - compulsive buying and external trash-talking - and the mediating role of brand attachment on these relationships.

Design/methodology/approach - Two studies were designed using SEM methodology. Study 1a was based on a mail survey of 280 respondents, whereas Study $1 \mathrm{~b}$ was based on an electronic survey of 152 respondents. Study $1 \mathrm{~b}$ was conducted to test the external validity of the research model.

Findings - In Study 1a, ideal self-congruence affects emotional brand attachment and in turn emotional brand attachment affects compulsive buying behaviour and external trash-talking. The mediation analysis indicates that emotional brand attachment mediates the relationships. Study $1 \mathrm{~b}$ offers support to the results of Study 1a.

Practical implications - From a practical point of view, this study is useful for policy makers seeking to regulate and prevent excessive consumerism. For marketers, they should understand that brand attachment leads to compulsive buying and external trash-talking, which may provide immediate benefit for the brand or the firm. However, marketers should understand that these two negative behaviours may harm the firm image and consumers' well-being in the long run.

Social implications - Apart from practical implications, firms should consider alleviating compulsive buying as it is harmful to society. Similarly, excessive external trash-talking may lead to physical aggression. Consumers expect firms to be socially responsible. Thus, firms should start conducting activities that promote responsible shopping and reduce external trash-talking.

Originality/value - The study highlights a dark side of ideal self-congruence and brand attachment. The results suggest that ideal self-congruence with the help of emotional brand attachment predicts compulsive buying behaviour and external trash-talking. This may not only damage brand image but also the consumers' well-being.
\end{abstract}

Keywords: Negative behaviour, external trash-talking, compulsive buying, brand attachment, ideal self-congruence

Paper type: Research paper 


\section{Introduction}

The self-concept theory posits that individuals have two different types of self, namely the actualself and ideal-self (Malär et al., 2011; Escalas \& Bettman, 2003). Actual-self refers to the individual's perceived reality of oneself, whereas ideal-self refers to the individual's aspirations of ideals and goals to be achieved in the future. Self-congruence refers to perceived personality fit between the consumer and the brand (Aaker, 1999). When the brand's image is congruent with the consumer's self-image, consumers are likely to establish strong emotional attachment and loyalty with the brand (Malär et al., 2011; Thomson et al., 2005; Park et al., 2010).

Many studies in the marketing literature focus on investigating the effects of selfcongruence on favourable consumer behaviours such as consumer satisfaction, brand love, favourable attitudes, Word-of-Mouth (WOM) and consumer loyalty (e.g. Ekinci \& Riley, 2003; Kressman et al., 2006; Ekinci et al., 2008; Nam et al., 2011; Wallace et al., 2017). A comprehensive review of the self-concept literature concludes that only the positive consumer behaviours are investigated as the consequences of self-congruence (e.g. Hosany and Martin, 2012). Although a few studies have begun to examine the relationship between self-concept, brand attachment and negative behaviours, they are limited. Brand attachment is defined as emotional bonding between a consumer and a brand. Brand attachment may trigger some negative consumer behaviour. For example Japutra et al. (2014) find that stronger brand attachment leads to a wide range of unwanted consequences including trash-talking, Schadenfreude and anti-brand actions. Johnson et al. (2011) state that when a brand becomes more self-relevant and the relationship with the brand ends, it is very likely that consumers could induce retaliatory behaviours such as brand 
hatred. Despite highlighting the dark side of brand attachment with regards to its negative behavioural consequences, these propositions have yet to be empirically tested.

This study addresses three research questions. First, does self-congruence lead to negative behaviours, namely compulsive buying and external trash-talking? Compulsive buying refers to a condition where individuals lose control and have irresistible impulse to buy excessively from the brand (Dittmar, 2005). When consumers purchase the brand compulsively it may seem to be an advantage to the brand, but this is not often beneficial for all members of the society. Compulsive buying can lead to a higher debt level, economic crisis and threaten the consumers' well-being (Gardarsdottir \& Dittmar, 2012; Schneider \& Kirchgasnner, 2009). Simons (2003) defines trashtalking as the action of offending one's competitor verbally. When the consumers have high propensity to conduct trash-talking, the brands could suffer as trash-talking can lead to physical aggression. When their consumers are stamped as troublemakers, the brand reputation could be damaged (Simons, 2003; Japutra et al., 2014). For example Colliander and Hauge-Wien (2013) show that trash-talking may backfire when a consumer defends his/her favourite brand aggressively through trash-talking. Second, does brand attachment influence compulsive buying and external trash-talking? Third, does brand attachment mediate the link between selfcongruence, compulsive buying and trash-talking?

The contribution of this study is three-fold. First, differing from extant research that predominantly examines the relationships between self-congruence and positive consequences (i.e consumer loyalty), the study investigates the effect of self-congruence on compulsive buying and external trash-talking. This is important because previous researchers regard compulsive buying 
and trash-talking as a viable concern due to their increasing predominance and negative consequences. To the best of our knowledge, empirical evidence is yet to be provided on whether higher self-self congruence can influence negative behaviours (e.g. Horvath \& Birgelen, 2015; Dittmar, 2005). Several studies in the realm of psychology suggest that individuals who aspire to move closer from their actual-self to ideal-self tend to conduct compulsive buying (e.g. Dittmar, 2005; Li et al., 2011). Trash-talking is different from negative WOM since it is the act of insulting rival brands (Hickman \& Ward, 2007). Several researchers argue that trash-talking is a form of oppositional brand loyalty (Marticotte et al., 2016; Japutra et al., 2014). Higher congruity between the self-concept and the brand image leads to higher level of loyalty (Wallace et al., 2017). We argue that such form of actions result in higher tendency to conduct trash-talking.

Second, this study investigates the effect of brand attachment on compulsive buying and trash talking. When consumers have strong attachment with brands they are likely to engage with compulsive buying through excessive purchasing and impulse buying. Compulsive buying and trash-talking are detrimental for the consumer's well-being and the brand image. Hence, this study enhances our understanding of whether self-congruence and brand attachment influence any form of negative consumer behaviour such as compulsive buying and trash-talking. Thirdly, this study investigates the mediating effect of brand attachment on the relationship between self-congruence and negative consumer behaviours. Previous studies assume a direct relationship between selfcongruence and favourable consumer behaviour due to stimulating positive emotions and selfconsistency (e.g. Usakli \& Baloglu, 2011; Kressman et al., 2006; Ekinci \& Riley, 2003; Sirgy, 1982). Hence, most of the studies suggest that the effects of self-congruence on consumer behaviours are direct (e.g. Wallace et al., 2017; Ahn et al., 2013). However, recent studies argue 
that the effect of self-congruence on consumer behaviour is not direct (e.g. Ekinci et al., 2008; Nam et al., 2011; Roy \& Rabbanee, 2015). In order to address this research gap, this study examines whether ideal self-congruence is capable of affecting consumer's negative behaviours directly or indirectly through the mediation of brand attachment.

Using the self-concept and brand attachment theory, the highlight of this study is in explaining how a consumer conducts compulsive buying and external trash-talking. This study reveals that ideal self-congruence fosters consumers' compulsive buying through the mediation of strong emotional bonding between consumers and brands. Furthermore, the findings of this study demonstrate that having high self-congruence and strong brand attachment increases consumers' propensity to exhibit trash-talking. The study offers research and managerial implications for academics, policy makers and marketing practitioners.

\section{Research Hypotheses}

\subsection{Self-congruence and emotional brand attachment}

The central assumption of the self-congruence theory is that consumers purchase brands to express their self-concept, whether it is actual or ideal (Ekinci et al., 2013; Aaker, 1999). In purchasing brands to achieve their ideal-self, consumers are guided by their self-enhancement motives to increase their self-esteem (Escalas \& Bettman, 2003). For instance, individuals whose actual selfself is monotone or calm would like to be more adventurous may purchase a Jeep Wrangler to reflect being adventurous. 
In his seminal work, Sirgy (1982) define self-congruence as the degree of fit between a consumer's own self-image and the brand image. He states that actual and ideal self-congruence predict consumers' purchasing behaviour. However, results from previous studies suggest that actual and ideal self-congruence are highly correlated (Kressmann et al., 2006). Generally speaking, ideal self-congruence is found to be a better predictor of brand purchasing behaviour than actual-self congruence. For instance, Graeff (1996) argues that ideal self-congruence is more relevant to publicly consumed products such as brands. Subsequently, Ekinci \& Riley (2003) show that ideal self-congruence strongly correlates with consumer attitude towards products, satisfaction and service quality. Hosany and Martin (2012) find ideal self-congruence to be the better predictor of favourable consumer behaviour than actual self-congruence. Thus, this study examines the role of ideal self-congruence in investigating the relationship between brand attachment, compulsive buying and trash-talking.

Brand attachment is defined as the emotional bond between a consumer and a brand (Malär et al., 2011). Brand attachment encompasses three dimensions: affection, passion and connection (Thomson et al., 2005). We propose that ideal self-congruence is positively associated with brand attachment. Consumers who purchase brands that are highly congruent with their ideal selfconcept tend to establish emotional connection with the brand (Malär et al., 2011). When brands help consumers in achieving their aspirations of who they would like to be (i.e. ideal self), the brands cater for the motivation of self-enhancement (Escalas \& Bettman, 2003). When brands are able to give them the aspirations of future goals, they perceive the brands to be congruent with their ideal-self. As a result, the emotional connections between consumers and the brands become 
stronger. This occurs because consumers feel that the brands have fulfilled their need to enrich the self (Park et al., 2013). Thus, the study proposes this hypothesis:

H1a. Ideal self-congruence positively affects brand attachment

\subsection{Self-Congruence, compulsive behaviour and external trash-talking}

Research on compulsive and impulsive consumers started in the 1980s. Impulsive buying is defined as spontaneous, unreflective, immediate and kinetic purchase that constitutes rapid decision-making and subjectivity for quick possession (Rook \& Fisher, 1995; Kacen \& Lee, 2002). Faber and O'Guinn (1989) state that compulsive consumers are those individuals who have the urge to buy products impulsively in order to escape from something, which they are unable to

control. Although the literature suggests that compulsive and impulsive buying are two distinct concepts, they are proximate (c.f. Flight et al., 2012; Ridgway et al., 2008). Impulsive buying, which includes buying urge and unplanned buying of products, is considered one of spending tendencies of compulsive buying (Desarbo and Edwards, 1996; Palan et al., 2011; Faber \& O’Guinn, 1989).

In this study, compulsive buying refers to consumers' inclination to buy the brands impulsively and/or excessively. According to Desarbo and Edwards (1996), the motive for impulse buying comes from an external trigger - the product itself on the shelf, whereas the motive for compulsive buying comes from an internal trigger - anxiety and/or trying to find an escape. It is suggested that willingness to close the discrepancy gap between actual and ideal-self may influence impulsive buying (c.f. Verplanken \& Sato, 2011). Dittmar (2005) finds that ideal-self 
buying motivation mediates the relationship between materialistic values and compulsive buying tendency. She argues that individuals who highly regard material possessions to enhance their ideal-self have higher prevalence to conduct compulsive buying. This study suggests that not only material possessions, but also brands are able to discern the prevalence of compulsive buying.

Higher congruity between the brand image and the ideal self-concept creates a state of excitement. Consumers feel excited because the brands help them in achieving their ideal selfconcept. Desarbo and Edwards (1996) note that higher level of excitement and impulsiveness leads to compulsive buying. Dittmar (2005) proposes that the motivation of materialism connected with the consumer's ideal self-concept predicts compulsive buying. Furthermore, Roberts et al. (2014) show that contingent self-esteem affects compulsive buying. Consumers' ideal-self is a reflection of self-enhancement motivation and self-esteem (Malär et al., 2011). Likewise, Zhang et al. (2014) show that greater neighbourhood social economic status increases material desires, which predicts more frequent impulsive buying. Therefore, compulsive buyers purchase things to achieve their ideal-self to express their ideal personality and improve their social image (Kukar-Kinney et al., 2012). They are predisposed to conduct compulsive buying because they would like to increase their self-esteem (Desarbo \& Edwards, 1996). A higher level of ideal self-congruence may increase the tendency to conduct compulsive buying. Thus, the present study proposes this hypothesis:

H1b. Ideal self-congruence positively affects compulsive buying

We propose that ideal self-congruence is associated with trash-talking. The phenomenon of trashtalking is similar but different to negative WOM (Japutra et al., 2014; Hickman \& Ward, 2007). 
Trash-talking refers to the action of offending rival brands verbally (Simons, 2003). It is a form of negative communications about rival brands initiated by members of brand groups as a result of the desire to positively differentiate their preferred brands from other brands (Japutra et al., 2014; Hickman \& Ward, 2007). Trash-talking can be divided into internal and external trash-talking (Hickman \& Ward, 2007). External trash-talking occurs within group members when a consumer talk negatively about rival brands outside his/her group, whereas internal trash-talking occurs within his/her group. This study examines external trash-talking which can have more delirious impact on the brand image than internal trash-talking.

Research on trash-talking usually came from the world of sport (e.g. Simons, 2003; Rainey \& Granito, 2010). However, these days, it is easy to find pertinent research outside the world of sport as consumers engage with trash talking about rival brands. Rainey and Granito (2010) show that one of the reasons for trash-talk is the role models (i.e. teammates). They note that young athletes mimic their role models to express their ideal self-concept. A state of excitement is created when there is a high congruity between the brand image and consumers' ideal self-concept. Excitement occurs because consumers feel that the brand helps them in achieving their ideal-self, which may lead the consumers to commit to the brand. When consumers exhibit higher level of attachment to a particular brand, trash-talking is more likely to occur (Hickman \& Ward 2007). Thus, we posit this hypothesis:

H1c. Ideal self-congruence positively affects external trash-talking

\subsection{Brand attachment and compulsive buying}


We propose that having strong attachment with brands influences compulsive buying. Horvath and Birgelen (2015) find initial evidence that three compulsive buyer displays emotional connection with the brand. When exhibiting compulsive buying, consumers do not seem to have clear conscious and control of what they are buying. Doron et al. (2009) find that consumer attachment are related to obsessive-compulsive disorder symptoms. People who are emotionally attached to brands are willing to use their personal resources (e.g. money or time) for purchasing the brand (Park et al., 2010). Kessous et al. (2015) note that consumer attachment and nostalgic status of the brand increase the tendency to collect the brand artefacts. Consumers seem to go back to the particular past events that they were cherished through brand purchasing. If brands are able to facilitate these kinds of experiences, consumers are strongly attached to those brands. Compulsive buyers purchase brands due to their emotional attachment with the brand (Kyrios et al., 2004). Thus, this study proposes this hypothesis:

H2. Brand attachment positively affects compulsive buying

\subsection{Brand attachment and external trash-talking}

Japutra et al. (2014) suggest that consumer attachment is a necessary condition for trash-talking. The link between brand attachment and trash-talking is being driven by consumers' sense of social identity motivated by self-categorisation, affective commitment and group-based self-esteem (Bergami \& Bagozzi, 2000). Muniz and Hamer (2001) argue that consumers exhibit trash-talking because they defend their social identity. If someone insults the brand, consumers consider this as an insult to their social identity (Colliander \& Hauge-Wien, 2013). Thus, these consumers tend to positively discriminate their brands in comparison to rival brands (Hickman \& Ward 2007). Also 
consumers conduct trash-talking because they are active member of the brand community (Hickman \& Ward, 2007). When someone downplays the brand, they feel it as a personal insult to their community (Muniz \& Hamer, 2001). Automatically they retaliate by downplaying the other brand. Thus, the present study proposes this hypothesis:

H3. Brand attachment positively affects external trash-talking

The conceptual framework and the research hypotheses are illustrated in Figure 1.

Insert Figure 1 Here

As can be seen from Figure 1, ideal self-congruence is positively associated with emotional brand attachment (H1a). In turn, emotional brand attachment is positively related to consumers' tendency to conduct compulsive buying (H2) and external trash-talking (H3). H1b and H1c account for the partial mediation effect of emotional brand attachment on the relationship between ideal self-congruence, compulsive buying and external trash-talking. Hence, it is proposed that ideal self-congruence is positively associated with compulsive buying and external trash-talking.

\section{The Studies}

Study 1a and Study $1 \mathrm{~b}$ have been undertaken to explore these propositions. Study 1a was based on a mail survey of 280 respondents within the UK. Using the Structural Equation Modelling (SEM) approach, the research hypotheses were tested. Study $1 \mathrm{~b}$ was conducted to assess the external and 
predictive validity of the research model. The data were based on an electronic survey of 152 respondents.

Altogether, from the 432 respondents, $62 \%$ were female, $36 \%$ were single and $48 \%$ were married. In terms of age-group, $21 \%$ were in the $16-24$ age-group, $16 \%$ were in the 25 - 34 agegroup, $19 \%$ were in the $35-44$ age group, $18 \%$ were in the $45-54$ age-group, $14 \%$ were in the 55 64 age group and the rest was in the 65 and above age-group. Regarding their income, $21 \%$ were in the $£ 20,000-£ 29,000,17 \%$ were in the $£ 10,000-£ 19,000$ and $16 \%$ were in the $£ 40,000-£ 59,999$ income bracket. According to the 2011 Census in the UK (ONS, 2013b), females accounted for $51 \%$ of the total population, $47 \%$ were married and $35 \%$ were single, whereas the mean age was 39.4 (age 16-29: 19\% and age 30-64: 46\%). In 2011/2012, the median household income was $£ 23,200$ (ONS, 2013a). Based on these, it could be concluded that the respondents of this study were good representation of the research population, who are consumers within the UK.

\section{Study 1a}

\subsection{Measures}

For the data collection, a questionnaire was developed for this study. The questions were derived from existing measurements based on review of previous published studies. Twelve general public respondents (UK consumers) were involved in pilot testing the questionnaire.

Ideal self-congruence was assessed using three items adapted from Malär et al. (2011) and Sirgy et al. (1997). Based on previous studies, self-congruence was measured using a direct-score 
formula. Initially, the respondents were asked to read a scenario paragraph (e.g. Nam et al., 2011; Ekinci et al., 2008):

"Take a moment to think about your favourite brand. Think about the kind of person who typically uses this brand. Imagine this person in your mind and then describe this person using one or more personal adjectives such as, stylish, classy, masculine, sexy, old, athletic, or whatever personal adjectives you can use to describe the typical user of this brand."

After reading the scenario type introduction, respondents were asked to assess ideal selfcongruence on a 7-point scale, anchored by (1) = strongly disagree and (7) $=$ strongly agree. An example of the items for ideal self-congruence is: "This brand is a mirror image of the person I would like to be". Emotional brand attachment was assessed using nine statements (reflecting affection, passion and connection) adapted from Thomson et al. (2005) and rated on a 7-point scale anchored by $(1)=$ describes poorly and $(7)=$ describes very well. The respondents were asked to rate these statements after reading the following instruction: "My feelings toward this brand can be characterised by". Compulsive buying was assessed using five statements adapted from Ridgway et al. (2008) and rated on a 7-point scale anchored by (1) = not very likely and (7) $=$ very likely. An example of the items for compulsive buying is: "I buy things from this brand that I don't need". External trash-talking was assessed using three items adapted from Hickman and Ward (2007) rated on a 7-point scale anchored by (1) = not very likely and (7) = very likely. An example of the items for external trash-talking is: "I talk about how negative I feel about competing brands to other people". The details of the measurements can be seen in Appendix A.

\subsection{Sample and procedure}


The mail survey containing the questionnaire and a return pre-paid envelope was distributed in different housing locations in the Southeast of UK, owing to its demographically diverse residential mix (Ahn et al., 2013). In total, 284 questionnaires were returned. After checking for incomplete responses, 280 questionnaires were deemed usable for the analysis.

Of these, $61.1 \%$ of the participants were women. For the participants' occupation, $28.9 \%$ were professionals, $15.4 \%$ were retired, $13.9 \%$ were students, $10.7 \%$ were either directors or senior officials and $8.2 \%$ were associates or technical workers. In terms of age group, $13.9 \%$ of the participants were in the $16-24,17.1 \%$ of the participants were in the $25-34,19.6 \%$ of the participants were in the $35-44,15.0 \%$ of the participants were in the $45-54,15.7 \%$ of the participants were in the 55-64, and the rest were 65 or above. $34.3 \%$ of the participants reported to have obtained undergraduate degrees. Participants reported their income, which ranged from less than $£ 10,000$ to more than $£ 100,000$, with many of them obtaining $£ 20,000$ to $£ 29,999$ (18.9\%) and less than $£ 10,000(17.9 \%)$.

\subsection{Data analysis and hypotheses testing}

The study adopted Structural Equation Modelling approach (SEM) to test the research model and research hypotheses by using AMOS 18 software. Before conducting the analysis, the normality of the data was checked through the skewness and kurtosis tests. Based on the results, the absolute values of the skewness and kurtosis of each item were around -1 and +1 , indicating that univariate normality was achieved. 
Following Anderson and Gerbing (1988), a measurement model was constructed to assess the validity and reliability of the measures. The fit statistics of the measurement model was satisfactory (Malhotra, 2010): $\mathrm{X}^{2}{ }_{(160)}=309.59, \mathrm{X}^{2} / \mathrm{df}=1.94, \mathrm{GFI}=.90, \mathrm{AGFI}=.87, \mathrm{NFI}=.91$, $\mathrm{TLI}=.95, \mathrm{CFI}=.96, \mathrm{RMSEA}=.06$ and SRMR $=.05)$. Appendix A provides a complete list of the measures. The composite reliability exceeds the threshold value of .60 (Bagozzi \& Yi, 1988) and Cronbach's alpha exceeds the threshold value of .60 (Malhotra, 2010), indicating satisfactory reliability (see Appendix A). All the factor loadings and average variance extracted (AVE) are above .50 indicating convergent validity is achieved (Fornell \& Larcker, 1981). Table 1 provides the correlation scores for the four constructs.

\section{Insert Table 1 Here}

Fornell and Larcker (1981) suggest comparing the AVE with the squared inter-construct correlation (SIC) to assess discriminant validity. The criterion for discriminant validity is when the AVE score is greater than the SIC score. Based on the results shown in Table 1, discriminant validity is achieved. Before testing the research hypotheses, common-method variance was checked. This is because in a study such as this, where data on both the antecedents and consequences are collected using similar types of response scales (e.g. Likert scales) from the same respondent, common-method variance may pose a problem (Du et al., 2007). Based on previous research (Du et al., 2007; Podsakoff et al., 2003), common-method variance was checked using Harman's single-factor test, which suggests that common-method variance poses a problem if (1) a single unrotated factor solution appears from the EFA test, or (2) one general factor accounts for the majority of the covariance among the measures. The unrotated factor solution revealed 4 
factors with Eigen values greater than 1 . The result accounts for $67.93 \%$ of the total variance, where the first factor accounts for $32.71 \%$ of the total variance. This suggests that common-method variance does not pose a significant problem, since there was no general factor in the unrotated structure (Du et al., 2007).

Next, the structural model was created. The fit statistics of the structural model $\left(\mathrm{X}_{(161)}^{2}=\right.$ $337.31, \mathrm{X}^{2} / \mathrm{df}=2.10, \mathrm{GFI}=.89, \mathrm{AGFI}=.86, \mathrm{NFI}=.91, \mathrm{TLI}=.94, \mathrm{CFI}=.95, \mathrm{RMSEA}=.06$ and SRMR $=.05)$ produced good fit. The results of the hypotheses testing are shown in Table 2.

Insert Table 2 Here

The results support $\mathrm{H} 1 \mathrm{a}(\mathrm{SPC}=0.47, \mathrm{p}<0.001)$. Hence, ideal self-congruence is positively associated with emotional brand attachment. H1b posits that ideal self-congruence positively affects compulsive buying and H1c states that ideal self-congruence positively affects external trash-talking. The results do not support these hypotheses $(\mathrm{H} 1 \mathrm{~b}, \mathrm{SPC}=0.04, \mathrm{p}>0.05$ and $\mathrm{H} 1 \mathrm{c}$, $\mathrm{SPC}=-0.01, \mathrm{p}>0.05)$. It is proposed in $\mathrm{H} 2$ that emotional brand attachment positively affects compulsive buying. This hypothesis is also supported by the results as shown in Table 2 (SPC = $0.28, \mathrm{p}<0.001)$. Hence the greater the emotional attachment with a particular brand, the more likely consumers to undertake compulsive buying. The results also support H3, which states that emotional brand attachment positively associated with external trash-talking $(\mathrm{SPC}=0.28, \mathrm{p}<$ 0.001). Stronger emotional brand attachment leads to higher propensity to conduct external trashtalking. 
Since the results do not support $\mathrm{H} 1 \mathrm{~b}$ and $\mathrm{H} 1 \mathrm{c}$, we conducted a mediation analysis. To test the mediation analysis, we performed a bootstrapping method via Preacher-Hayes INDIRECT script (Preacher \& Hayes, 2008; Zhao et al., 2010). The score for each construct was aggregated and bootstrapping procedures (5000 samples) were conducted. The other dependent variable was put as covariate. The direct effect of ideal self-congruence on emotional brand attachment $(\beta=$ $0.34, \mathrm{SE}=0.04, \mathrm{t}=7.79, \mathrm{p}<0.001)$ as well as the direct effect of emotional brand attachment on compulsive buying $(\beta=0.17, \mathrm{SE}=0.08, \mathrm{t}=2.20, \mathrm{p}<0.05)$ are significant. A confidence interval (CI) that excludes zero for the indirect effect reveals support that emotional brand attachment mediates the relationships of ideal self-congruence on compulsive buying $(\mathrm{a} \times \mathrm{b}=5.90 \%, \mathrm{SE}=$ $0.03,95 \% \mathrm{CI}[0.01,0.13])$. Since the direct effect of ideal self-congruence on compulsive buying is not significant $(\beta=0.08, \mathrm{SE}=0.06, \mathrm{t}=1.25, \mathrm{p}>0.05)$, the mediation is indirect-only mediation (Zhao et al., 2010).

The direct effect of ideal self-congruence on emotional brand attachment $(\beta=0.34, \mathrm{SE}=$ $0.04, \mathrm{t}=7.56, \mathrm{p}<0.001)$ as well as the direct effect of emotional brand attachment on compulsive buying $(\beta=0.22, \mathrm{SE}=0.09, \mathrm{t}=2.56, \mathrm{p}<0.05)$ is significant. A confidence interval $(\mathrm{CI})$ that excludes zero for the indirect effect reveals support that emotional brand attachment mediates the relationships of ideal self-congruence on compulsive buying $(\mathrm{a} \times \mathrm{b}=7.41 \%, \mathrm{SE}=0.03,95 \% \mathrm{CI}$ $[0.02,0.15])$. Since the direct effect of ideal self-congruence on compulsive buying is not significant $(\beta=-0.00, \mathrm{SE}=0.07, \mathrm{t}=-0.04, \mathrm{p}>0.05)$, the mediation is indirect-only mediation (Zhao et al., 2010).

\section{Study $1 b$}


The objective of Study $1 \mathrm{~b}$ is to assess external and predictive validity of the model. Woodside (2013) advocates the need to test for predictive validity and not just fit validity. One way of testing the external and predictive validity is using additional samples of cases (Woodside, 2015). Hence, we replicated Study 1a with additional samples.

\subsection{Measures, sample and procedure}

The measures for ideal self-congruence, emotional brand attachment, compulsive buying, and external trash-talking were identical to Study 1a. An online questionnaire was developed using SurveyMonkey and distributed through several different media and fora (e.g. dailymail.co.uk) in the UK. An email invitation containing the link to the electronic survey was posted on these media and fora. After checking for incomplete answers, 152 questionnaires were deemed usable for analysis.

Of these, $61.2 \%$ of the participants were women. For the participants' occupation, $40.1 \%$ were students, $21.7 \%$ were professionals, $11.8 \%$ were either directors or senior officials and $8.6 \%$ were administrative or secretarial workers. In terms of age group, $33.6 \%$ of the participants were in the $16-24,14.5 \%$ of the participants were in the $25-34,17.1 \%$ of the participants were in the 35 $44,23.0 \%$ of the participants were in the $45-54,9.9 \%$ of the participants were in the $55-64$, and the rest were 65 or above. $26.3 \%$ of the participants reported to have obtained undergraduate degrees. Participants reported their income, which ranged from less than $£ 10,000$ to more than $£ 100,000$, with many of them obtaining $£ 20,000$ to $£ 29,999$ (16.4\%) and less than $£ 10,000$ $(34.2 \%)$ 


\subsection{Data analysis and hypotheses testing}

The fit statistics of the measurement model was satisfactory (Malhotra, 2010): $\mathrm{X}_{(160)}^{2}=284.52$, $\mathrm{X}^{2} / \mathrm{df}=1.78, \mathrm{GFI}=.85, \mathrm{AGFI}=.80, \mathrm{NFI}=.86, \mathrm{TLI}=.92, \mathrm{CFI}=.93, \mathrm{RMSEA}=.07$ and $\mathrm{SRMR}$ $=.06)$. The composite reliability and Cronbach's alpha values of each construct are between .75 and .93 , indicating satisfactory reliability. All the factor loadings and average variance extracted (AVE) scores are between .58 and .83 . These findings indicate that convergent validity is achieved. The AVE scores are greater than the SIC scores, indicating discriminant validity is achieved. The correlations between constructs range from .07 to .55 , which are similar to Study $1 \mathrm{a}$.

Next, the structural model was created. The fit statistics of the structural model $\left(\mathrm{X}_{(161)}^{2}=\right.$ 292.63, $\mathrm{X}^{2} / \mathrm{df}=1.82, \mathrm{GFI}=.85, \mathrm{AGFI}=.80, \mathrm{NFI}=.86, \mathrm{TLI}=.92, \mathrm{CFI}=.93, \mathrm{RMSEA}=.07$ and SRMR $=.08$ ) produced a good fit. The results of the hypotheses testing are shown in Table 3.

Insert Table 3 Here

The results in Study 1b provide support for Study 1a. Hence, ideal self-congruence (H1a) positively affects emotional brand attachment $(\mathrm{SPC}=0.55, \mathrm{p}<0.001)$. Emotional brand attachment positively affects compulsive buying $(\mathrm{H} 2$ : $\mathrm{SPC}=0.43, \mathrm{p}<0.001)$ and external trashtalking $(\mathrm{H} 3$ : $\mathrm{SPC}=0.33, \mathrm{p}<0.01)$. Similar to Study 1a, the effects of ideal self-congruence on compulsive buying behaviour $(\mathrm{H} 1 \mathrm{~b}$ : $\mathrm{SPC}=-0.06, \mathrm{p}>0.05)$ and external trash-talking $(\mathrm{H} 1 \mathrm{c}: \mathrm{SPC}$ $=-0.12, \mathrm{p}>0.05)$ are not statistically significant. 
To test the mediation analysis, we performed a bootstrapping method via Preacher-Hayes INDIRECT script (Preacher \& Hayes, 2008; Zhao et al., 2010). The score for each construct was aggregated and bootstrapping procedures (5000 samples) were conducted. To test whether emotional brand attachment mediates the link between ideal self-congruence and compulsive buying, external trash-talking was included as covariate. The direct effect of ideal self-congruence on emotional brand attachment $(\beta=0.40, \mathrm{SE}=0.06, \mathrm{t}=6.81, \mathrm{p}<0.001)$ as well as the direct effect of emotional brand attachment on compulsive buying $(\beta=0.27, \mathrm{SE}=0.11, \mathrm{t}=2.46, \mathrm{p}<0.05)$ are statistically significant. A confidence interval (CI) that excludes zero for the indirect effect reveals support that emotional brand attachment mediates the relationships of ideal self-congruence on compulsive buying $(\mathrm{a} \times \mathrm{b}=10.86 \%, \mathrm{SE}=0.04,95 \% \mathrm{CI}[0.03,0.20])$. Since the direct effect of ideal self-congruence on compulsive buying is not significant $(\beta=0.03, \mathrm{SE}=0.09, \mathrm{t}=0.31, \mathrm{p}>$ 0.05), the mediation is indirect-only mediation (Zhao et al., 2010).

The bootstrapping method was performed to further test whether emotional brand attachment mediates the link between ideal self-congruence and external trash-talking. Compulsive buying was included as covariate. The direct effect of ideal self-congruence on brand attachment $(\beta=0.38, \mathrm{SE}=0.06, \mathrm{t}=6.54, \mathrm{p}<0.001)$ as well as the direct effect of emotional brand attachment on compulsive buying $(\beta=0.22, \mathrm{SE}=0.12, \mathrm{t}=1.80, \mathrm{p}<0.05)$ are statistically significant. A confidence interval (CI) that includes zero for the indirect effect reveals support that emotional brand attachment does not mediate the relationships of ideal self-congruence on external trash-talking ( $\mathrm{a} \times \mathrm{b}=8.33 \%, \mathrm{SE}=0.05,95 \% \mathrm{CI}[-0.01,0.19])$. However, the confidence interval is close to zero and the direct effect of ideal self-congruence on external trash-talking is not 
significant $(\beta=-0.04, \mathrm{SE}=0.10, \mathrm{t}=-0.44, \mathrm{p}>0.05)$. One explanation is the small sample size. Thus, we could still infer that emotional brand attachment mediates the relationship.

\section{Post Hoc Analysis}

To test the robustness of the results, we conducted further tests. First, we pooled the data from Study 1a and Study 1b. Thus, there were 432 respondents. Second, we formed ideal selfcongruence into high and low group, based on the mean score. For respondents that score above the mean score, they were categorised into high ideal self-congruence group, whereas the rest were categorised into low ideal self-congruence group. Third, we tested the direct effects of ideal selfcongruence on compulsive buying and external trash-talking using ANOVA (bootstrap 5000 samples). The results of the ANOVA analysis show that ideal self-congruence has a significant main effect on compulsive buying $\left(\mathrm{M}_{\text {isc high }}=2.66\right.$ vs. $\left.\mathrm{M}_{\text {isc low }}=2.27, \mathrm{~F}=7.41, \mathrm{p}<0.01\right)$, whereas it does not have a significant main effect on external trash-talking $\left(\mathrm{M}_{\text {isc high }}=3.11 \mathrm{vs}\right.$. $\mathrm{M}_{\text {isc low }}=$ $2.81, \mathrm{~F}=3.62, \mathrm{p}>0.05)$. Based on these results, we continued to analyse the mediation effect of emotional brand attachment.

To test the mediation effect of emotional brand attachment, we conducted a mediation analysis using bootstrapping method via PROCESS model 4 (Hayes \& Preacher, 2014). The independent variable was the categorised ideal self-congruence, the mediator was emotional brand attachment, the outcome variable was compulsive buying, and external trash-talking was put as the covariate. The results show that there is no direct effect of ideal self-congruence on compulsive buying $(\beta=0.12, \mathrm{SE}=0.14, \mathrm{t}=0.82, \mathrm{p}>0.05)$. However, there is indirect effect of ideal selfcongruence on compulsive buying since the confidence interval excludes zero $(\beta=0.19, \mathrm{SE}=$ 
$0.06,95 \%$ CI $[0.09,0.32])$. The results provide support that emotional brand attachment mediates the relationship between ideal self-congruence and compulsive buying behaviour.

Next, we test the mediation of emotional brand attachment for external trash-talking. The independent variable was categorised ideal self-congruence, with the mediator as emotional brand attachment, the outcome variable was external trash-talking, and compulsive buying was put as the covariate. The results show that there is no direct effect of ideal self-congruence on external trash-talking $(\beta=-0.01, \mathrm{SE}=0.16, \mathrm{t}=-0.04, \mathrm{p}>0.05)$. However, there is indirect effect of ideal self-congruence on external trash-talking since the confidence interval excludes zero $(\beta=0.17, \mathrm{SE}$ $=0.06,95 \% \mathrm{CI}[0.06,0.31])$. The results provide support that emotional brand attachment mediates the relationship between ideal self-congruence and external trash-talking.

\section{Discussion}

\subsection{Theoretical contribution}

Extant research suggests that self-congruence and brand attachment influence favourable consumer behaviours that are advantageous for the brand (e.g. Wallace et al., 2017; Japutra et al., 2016; Park et al., 2013). Interestingly, our study findings provide evidence that this is not always

the case. Hence, this study enlightens the literature by suggesting that having high self-congruity and strong brand attachment is likely to increase compulsive buying and external trash-talking.

This study contributes to the body of literature dealing with the outcomes of ideal selfcongruence and brand attachment in a number of ways. Previously the literature on selfcongruence notes that self-congruence affects positive behaviours (see Hosany \& Martin, 2012). 
However, our results suggest that ideal self-congruence is capable of affecting compulsive buying and external trash-talking through emotional brand attachment which are potentially harmful for the long-term prosperity of the brand and consumer's well-being (Horvath \& Birgelen, 2015; Japutra et al., 2014; Gardarsdottir \& Dittmar, 2012; Schneider \& Kirchgasnner, 2009). Dittmar (2005) argues that the motivation of materialism to achieve an ideal-self is the predictor of compulsive buying. Our study extends this literature by showing that when the brand's image is in line with the consumer's ideal self-concept, the tendency to conduct compulsive buying increases.

Our work shows that ideal self-congruence does not directly affect compulsive buying, but indirectly affects compulsive buying through emotional brand attachment. Thus, this study contributes to explaining how the mechanism of ideal self-congruence operates on predicting compulsive buying. Meanwhile, the findings of this study contribute to the growing literature on the dark side of brand attachment (Japutra et al., 2014; Johnson et al., 2012; Johnson et al., 2011). The results confirm that emotional brand attachment has a direct and positive effect on compulsive buying. This means that emotional brand attachment fully mediates the relationship between ideal self-congruence and compulsive buying. Previous studies note that consumers tend to conduct compulsive buying due to their personal connection (e.g. nostalgic status) with the brand (Kessous et al., 2015; Horvath and Birgelen, 2015). We extend this finding by showing that emotional brand attachment including personal connection, affection and passion are important in predicting compulsive buying. 
In addition, this study contributes to the literature dealing with the motivation of trashtalking. Our findings show that ideal self-congruence and emotional brand attachment influence external trash-talking. Previous studies note that trash-talking is the result of being affectively committed with the brand and actively engaged in the brand community (Japutra et al., 2014; Hickman \& Ward, 2007; Muniz \& Hamer, 2001). We extend these studies by showing that trashtalking could occur without participating in the brand community. When consumers feel passionately and affectionately connected to the brand due to their ideal self-concept, they tend to defend the brand through trash-talking.

\subsection{Managerial implications}

It has been noted that material consumption, particularly uncontrolled buying, decreases individual economic and subjective well-being (Zhang et al., 2014). Thus, it is important for policy makers to understand the factors that will lead to compulsive buying. Policy makers should regulate firms - such as on the creation of advertisements that foster exaggeration on fostering their ideal-self since ideal self-congruence directly influence strong attachment and indirectly influence compulsive buying. Advertisements featuring thin models are related to adolescent girls' body dissatisfaction and eating disorders (Halliwell et al., 2005; Bell et al., 2007).

Firms should pay attention to their consumers' compulsive buying, since in the long run this could harm the brand image. Brand managers should be aware of the consequences for brand reputation when their consumers are engaging in compulsive buying. Horvath and Birgelen (2015) note that when firms condone compulsive buying, they are facing ethical dilemmas due to their social responsibilities. Subsequently, firms should be weary when a relationship ends, as 
compulsive consumers exhibit higher anxiety (Horvath and Birgelen, 2015) and are more likely to conduct anti-brand actions (Johnson et al., 2012; Japutra et al., 2014). Similarly, the rivalry in the form of trash-talking cause emotional distress to the consumers who engaged in the conflicts (Ewing et al., 2013). Managers should try to reduce emotional distress in order to increase their consumers' well-being.

\subsection{Limitations and further research}

Although this work highlights important contributions to the marketing literature, it is not without its limitations. This study makes inferences based on a cross-sectional data in a specific culture UK respondents. Thus, the study should be replicated with consumers from different cultures to increase its generalisability. Badgaiyan and Verna (2014) posit that personality traits, shopping enjoyment and materialism, apart from culture, affect impulsive buying behaviour. It would be worthwhile checking the role of these variables in the conceptual model proposed in this paper.

Researchers argue that extrinsic life aspiration is related to the propensity of conducting compulsive buying (Otero-Lopez \& Villardefrancos, 2015). These authors note that the high compulsive buying group attributed higher importance toward financial success, image, popularity and conformity. These attributes show individuals' aspirations to reach the ideal-self. It would be an interesting avenue to examine the role of extrinsic goals in relation to ideal self-congruence and emotional brand attachment on compulsive buying.

This study measures brand attachment using a unidimensional construct that covers only emotional bonding. A recent study has argued that brand attachment does not only cover emotional 
bonding but also cognitive bonding, reflecting brand-self connection and brand prominence (Park et al., 2010). Future studies should measure brand attachment that reflects both cognitive and emotional bonding. Mende et al. (2013) argue that consumers are being guided by their attachment styles in the relationships with firms. Thus, attachment styles might be taken into account as moderating variables.

In the current study, consumers responded to questions that were specific to their chosen favourite brand across various categories. Although the diversity of brands' categories provides important implications in general, further studies should focus on several specific categories of brands that have high turnover (e.g. fashion brands). Marticotte et al. (2016) argue that brand rivalries provide excellent opportunity to examine consumer attitudes and behaviours linked to oppositional brand referrals (e.g. trash-talking). Thus, it is relevant for scholars to examine the research framework in the context of brand rivalries (e.g. Sony PlayStation vs. Microsoft Xbox). 


\section{References}

Aaker, J. (1999). The malleable self: The role of self-expression in persuasion. Journal of Marketing Research, 36(2), 45-57.

Ahn, T., Ekinci, Y., \& Li, G. (2013). Self-congruence, functional congruence, and destination choice. Journal of Business Research, 66(6), 719-723.

Anderson, J. C., \& Gerbing, D. W. (1988). Structural equation modeling in practice: A review and recommended two-step approach. Psychological Bulletin, 103(3), 411.

Badgaiyan, A. J., \& Verma, A. (2014). Intrinsic factors affecting impulsive buying behaviourEvidence from India. Journal of Retailing and Consumer Services, 21(4), 537-549.

Bagozzi, R. P., \& Yi, Y. (1988). On the evaluation of structural equation models. Journal of the Academy of Marketing Science, 16(1), 74-94.

Baron, R. M., \& Kenny, D. A. (1986). The moderator-mediator variable distinction in social psychological research: Conceptual, strategic, and statistical considerations. Journal of Personality and Social Psychology, 51(6), 1173.

Bell, B. T., Lawton, R., \& Dittmar, H. (2007). The impact of thin models in music videos on adolescent girls' body dissatisfaction. Body Image, 4(2), 137-145.

Bergami, M., \& Bagozzi, R. P. (2000). Self-categorization, affective commitment and group selfesteem as distinct aspects of social identity in the organization. British Journal of Social Psychology, 39(4), 555-577.

Colliander, J., \& Hauge Wien, A. (2013). Trash talk rebuffed: consumers' defense of companies criticized in online communities. European Journal of Marketing, 47(10), 1733-1757.

Desarbo, W. S., \& Edwards, E. A. (1996). Typologies of compulsive buying behavior: A constrained clusterwise regression approach. Journal of Consumer Psychology, 5(3), 231-262.

Dittmar, H. (2005). A new look at" compulsive buying": Self-discrepancies and materialistic values as predictors of compulsive buying tendency. Journal of Social and Clinical Psychology, 24(6), 832.

Dittmar, H., Long, K., \& Bond, R. (2007). When a better self is only a button click away: associations between materialistic values, emotional and identity-related buying motives, and compulsive buying tendency online. Journal of Social and Clinical Psychology, 26(3), 334-361. Doron, G., Moulding, R., Kyrios, M., Nedeljkovic, M., \& Mikulincer, M. (2009). Adult attachment insecurities are related to obsessive compulsive phenomena. Journal of Social and Clinical Psychology, 28(8), 1022-1049.

Du, S., Bhattacharya, C. B., \& Sen, S. (2007). Reaping relational rewards from corporate social responsibility: The role of competitive positioning. International Journal of Research in Marketing, 24(3), 224-241.

Ekinci, Y., Dawes, P. L., \& Massey, G. R. (2008). An extended model of the antecedents and consequences of consumer satisfaction for hospitality services. European Journal of Marketing, 42(1/2), 35-68.

Ekinci, Y., \& Riley, M. (2003). An investigation of self-concept: actual and ideal self-congruence compared in the context of service evaluation. Journal of Retailing and Consumer Services, 10(4), 201-214.

Ekinci, Y., Sirakaya-Turk, E., \& Preciado, S. (2013). Symbolic consumption of tourism destination brands. Journal of Business Research, 66(6), 711-718.

Escalas, J. E., \& Bettman, J. R. (2003). You Are What They Eat: The Infulence of Reference Groups on Consumers' Connections to Brands. Journal of Consumer Psychology, 13(3), 339-348. 
Faber, R. J., \& O'Guinn, T. C. (1988). Compulsive consumption and credit abuse. Journal of Consumer Policy, 11(1), 97-109.

Flight, R. L., Rountree, M. M., \& Beatty, S. E. (2012). Feeling the urge: Affect in impulsive and compulsive buying. Journal of Marketing Theory and Practice, 20(4), 453-466.

Fornell, C., \& Larcker, D. F. (1981). Evaluating structural equation models with unobservable variables and measurement error. Journal of Marketing Research, 39-50.

Garðarsdóttir, R. B., \& Dittmar, H. (2012). The relationship of materialism to debt and financial well-being: The case of Iceland's perceived prosperity. Journal of Economic Psychology, 33(3), 471-481.

Halliwell, E., Dittmar, H., \& Howe, J. (2005). The impact of advertisements featuring ultra - thin or average - size models on women with a history of eating disorders. Journal of Community \& Applied Social Psychology, 15(5), 406-413.

Hayes, A. F., \& Preacher, K. J. (2014). Statistical mediation analysis with a multicategorical independent variable. British Journal of Mathematical and Statistical Psychology, 67(3), 451-470. Hickman, T., \& Ward, J. (2007). The dark side of brand community: Inter-group stereotyping, trash talk, and schadenfreude. Advances in Consumer Research, 34, 314.

Horváth, C., \& Birgelen, M. V. (2015). The role of brands in the behavior and purchase decisions of compulsive versus noncompulsive buyers. European Journal of Marketing, 49(1/2), 2-21.

Hosany, S., \& Martin, D. (2012). Self-image congruence in consumer behavior. Journal of Business Research, 65(5), 685-691.

Japutra, A., Ekinci, Y., Simkin, L., \& Nguyen, B. (2014). The dark side of brand attachment: A conceptual framework of brand attachment's detrimental outcomes. The Marketing Review, 14(3), 245-264.

Japutra, A., Ekinci, Y., \& Simkin, L. (2016). Tie the knot: Building stronger consumers' attachment toward a brand. Journal of Strategic Marketing, 1-18.

Johnson, A. R., Matear, M., \& Thomson, M. (2011). A coal in the heart: Self-relevance as a postexit predictor of consumer anti-brand actions. Journal of Consumer Research, 38(1), 108-125.

Johnson, A. R., Whelan, J., \& Thomson, M. (2012). Why brands should fear fearful consumers: how attachment style predicts retaliation. Journal of Consumer Psychology, 22(2), 289-298.

Kacen, J. J., \& Lee, J. A. (2002). The influence of culture on consumer impulsive buying behavior. Journal of Consumer Psychology, 12(2), 163-176.

Kessous, A., Roux, E., \& Chandon, J. L. (2015). Consumer-Brand Relationships: A Contrast of Nostalgic and Non - Nostalgic Brands. Psychology \& Marketing, 32(2), 187-202.

Kressmann, F., Sirgy, M. J., Herrmann, A., Huber, F., Huber, S., \& Lee, D. J. (2006). Direct and indirect effects of self-image congruence on brand loyalty.Journal of Business Research, 59(9), 955-964.

Kukar-Kinney, M., Ridgway, N. M., \& Monroe, K. B. (2012). The role of price in the behavior and purchase decisions of compulsive buyers. Journal of Retailing, 88(1), 63-71.

Kyrios, M., Frost, R. O., \& Steketee, G. (2004). Cognitions in compulsive buying and acquisition. Cognitive Therapy and Research, 28(2), 241-258.

Li, D., Liau, A., \& Khoo, A. (2011). Examining the influence of actual-ideal self-discrepancies, depression, and escapism, on pathological gaming among massively multiplayer online adolescent gamers. Cyberpsychology, Behavior, and Social Networking, 14(9), 535-539.

Malär, L., Krohmer, H., Hoyer, W. D., \& Nyffenegger, B. (2011). Emotional brand attachment and brand personality: The relative importance of the actual and the ideal self. Journal of Marketing, 75(4), 35-52. 
Malhotra, N. K. (2010). Marketing Research: An Applied Orientation $6^{\text {th }}$ ed. London: Pearson Education.

Marticotte, F., Arcand, M., \& Baudry, D. (2016) The impact of brand evangelism on oppositional referrals towards a rival brand. Journal of Product and Brand Management, 25(6), 538-549.

Muniz, A. M., \& Hamer, L. O. (2001). Us versus them: Oppositional brand loyalty and the cola wars. Advances in Consumer Research, 28, 355-361.

Nam, J., Ekinci, Y., \& Whyatt, G. (2011). Brand equity, brand loyalty and consumer satisfaction. Annals of Tourism Research, 38(3), 1009-1030.

O'Guinn, T. C., \& Faber, R. J. (1989). Compulsive buying: A phenomenological exploration. Journal of Consumer Research, 147-157.

ONS (2013a). Median Household Income Fell 3.8\% between 2007/08 and 2011/12. Available at: http://www.ons.gov.uk/ons/rel/household-income/middle-incomehouseholds/1977---2011-

12/sty-middle-income-households.html (accessed 23rd June 2014).

ONS (2013b). Who We Are? How We Live? What We Do? Available at: http://www.ons.gov.uk/ons/guidemethod/census/2011/index.html?utm_source=twitterfeed\&utm medium=twitter (accessed 23rd June 2014).

Otero-López, J. M., \& Villardefrancos, E. (2015). Compulsive buying and life aspirations: An analysis of intrinsic and extrinsic goals. Personality and Individual Differences, 76, 166-170.

Palan, K. M., Morrow, P. C., Trapp, A., \& Blackburn, V. (2011). Compulsive buying behavior in college students: the mediating role of credit card misuse.Journal of Marketing Theory and Practice, 19(1), 81-96.

Park, C. W., Eisingerich, A. B., \& Park, J. W. (2013). Attachment-aversion (AA) model of customer-brand relationships. Journal of Consumer Psychology, 23(2), 229-248.

Park, C. W., MacInnis, D. J., Priester, J., Eisingerich, A. B., \& Iacobucci, D. (2010). Brand attachment and brand attitude strength: Conceptual and empirical differentiation of two critical brand equity drivers. Journal of Marketing, 74(6), 1-17.

Podsakoff, P. M., MacKenzie, S. B., Lee, J. Y., \& Podsakoff, N. P. (2003). Common method biases in behavioral research: a critical review of the literature and recommended remedies. Journal of Applied Psychology, 88(5), 879.

Rainey, D. W., \& Granito, V. (2010). Normative rules for trash talk among college athletes: An exploratory study. Journal of Sport Behaviour, 33(3), 276.

Ridgway, N. M., Kukar-Kinney, M., \& Monroe, K. B. (2008). An expanded conceptualization and a new measure of compulsive buying. Journal of Consumer Research, 35(4), 622-639.

Roberts, J. A., Manolis, C., \& Pullig, C. (2014). Contingent self-esteem, self-presentational concerns, and compulsive buying. Psychology \& Marketing, 31(2), 147-160.

Rook, D. W., \& Fisher, R. J. (1995). Normative influences on impulsive buying behavior. Journal of Consumer Research, 305-313.

Roy, R., \& Rabbanee, F. K. (2015). Antecedents and consequences of self-congruity. European Journal of Marketing, 49(3/4), 444-466.

Schneider, F., \& Kirchgässner, G. (2009). Financial and world economic crisis: What did economists contribute? Public Choice, 140(3-4), 319-327.

Simons, H. D. (2003). Race and penalized sports behaviors. International Review for the Sociology of Sport, 38(1), 5-22.

Sirgy, M. J. (1982). Self-concept in consumer behavior: A critical review. Journal of Consumer Research, 287-300. 
Sirgy, M. J., Grewal, D., Mangleburg, T. F., Park, J. O., Chon, K. S., Claiborne, C. B., ... \& Berkman, H. (1997). Assessing the predictive validity of two methods of measuring self-image congruence. Journal of the Academy of Marketing Science, 25(3), 229-241.

Thomson, M., MacInnis, D. J., \& Park, C. W. (2005). The ties that bind: Measuring the strength of consumers' emotional attachments to brands. Journal of Consumer Psychology, 15(1), 77-91. Usakli, A., \& Baloglu, S. (2011). Brand personality of tourist destinations: An application of selfcongruity theory. Tourism Management, 32(1), 114-127.

Verplanken, B., \& Sato, A. (2011). The psychology of impulse buying: An integrative selfregulation approach. Journal of Consumer Policy, 34(2), 197-210.

Wallace, E., Buil, I., \& de Chernatony, L. (2017). Consumers' self-congruence with a 'Liked'brand: cognitive network influence and brand outcomes. European Journal of Marketing, 51(2).

Woodside, A. G. (2013). Moving beyond multiple regression analysis to algorithms: Calling for adoption of a paradigm shift from symmetric to asymmetric thinking in data analysis and crafting theory. Journal of Business Research, 66(4), 463-472.

Woodside, A. G. (2015). Visualizing $\bullet$ matching $\bullet$ generalizing: Case identification hypotheses and case-level data analysis. Australasian Marketing Journal (AMJ), 23(3), 246-258.

Zhang, J. W., Howell, R. T., \& Howell, C. J. (2014). Living in wealthy neighborhoods increases material desires and maladaptive consumption. Journal of Consumer Culture, 1469540514521085. 
Figure 1: Linking ideal self-congruence and emotional brand attachment to compulsive buying behaviour and external trashtalking

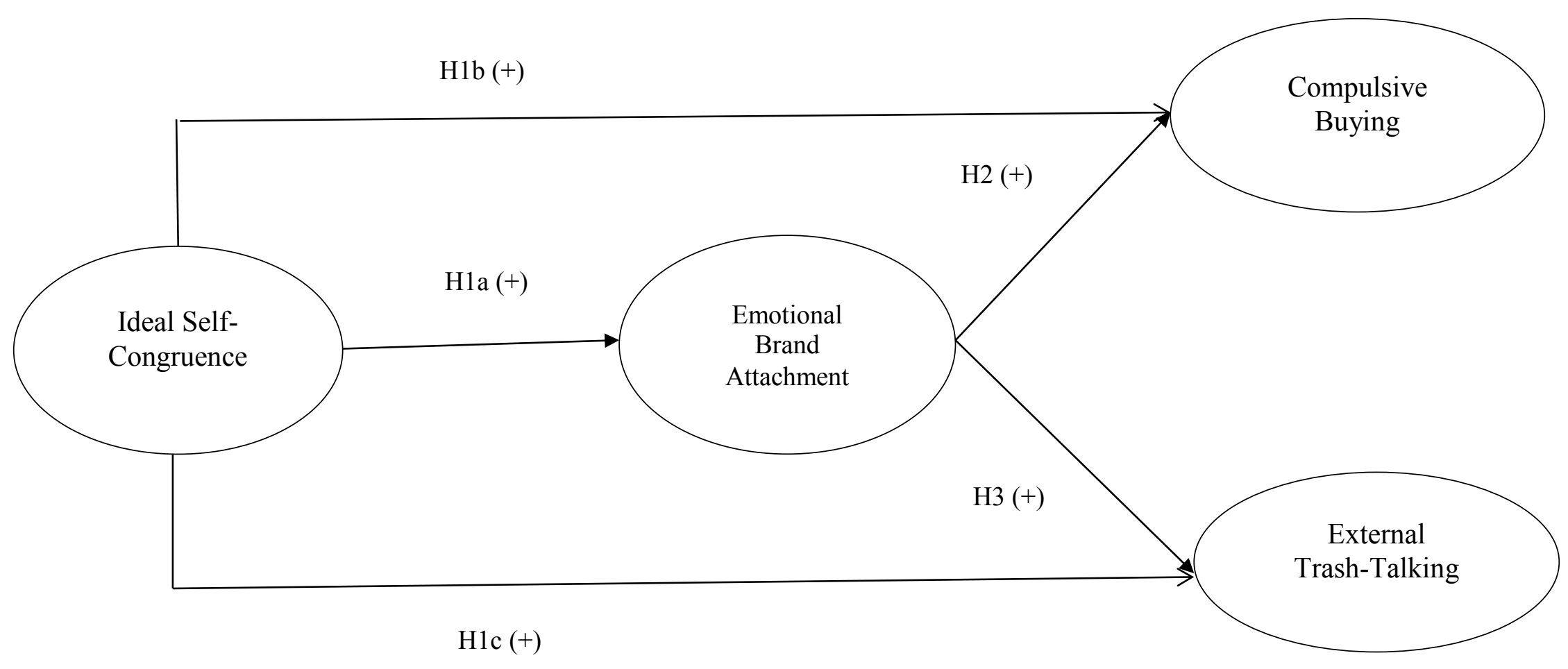


Table 1: Relationship between constructs for Study 1a

\begin{tabular}{llcccc}
\hline \multirow{2}{*}{ Construct scale } & \multicolumn{4}{c}{ Correlation } \\
\cline { 2 - 6 } & 1 & 2 & 3 & 4 \\
\hline 1 & Ideal self-congruence & $\mathbf{. 7 2}$ & .22 & .03 & .01 \\
2 & Emotional brand attachment & .47 & $\mathbf{. 8 0}$ & .08 & .07 \\
3 & Compulsive buying & .17 & .29 & $\mathbf{. 8 8}$ & .17 \\
4 & External trash talking & .12 & .26 & .41 & $\mathbf{. 7 9}$
\end{tabular}

Note: The diagonal values in bold indicate the average variances extracted (AVE). The scores in the lower diagonal indicate inter-construct correlation (IC) and the scores in the upper diagonal indicate squared inter-construct correlation (SIC). 
Table 2: Results of the hypotheses testing for Study 1a

\begin{tabular}{llcc}
\hline \multicolumn{2}{c}{ Relationships } & SPC & t-value \\
\hline H1a $\quad$ Ideal self-congruence $\rightarrow$ Emotional brand attachment & .47 & $6.70^{* * *}$ \\
H1b $\quad$ Ideal self-congruence $\rightarrow$ Compulsive buying & .04 & $.56^{\text {ns }}$ \\
H1c $\quad$ Ideal self-congruence $\rightarrow$ External trash-talking & -.01 & $-.16^{\mathrm{ns}}$ \\
H2 $\quad$ Emotional brand attachment $\rightarrow$ Compulsive buying & .28 & $3.37^{* * *}$ \\
H3 $\quad$ Emotional brand attachment $\rightarrow$ External trash-talking & .28 & $3.52^{* * *}$ \\
Variance explained $\left(\mathrm{R}^{2}\right)$ & & \\
Emotional brand attachment & & .22 \\
Compulsive buying & & .09 \\
External trash-talking & & .07
\end{tabular}

Note: $\mathrm{SPC}=$ Standardized Path Coefficient; ${ }^{\text {ns }}$ not significant, ${ }^{* *} p<.01,{ }^{* * *} p<.001$ 
Table 3: Results of the hypotheses testing for Study $1 \mathrm{~b}$

\begin{tabular}{llcc}
\hline & Relationships & SPC & t-value \\
\hline H1a & Ideal self-congruence $\rightarrow$ Brand attachment & .55 & $5.46^{* * *}$ \\
H1b $\quad$ Ideal self-congruence $\rightarrow$ Compulsive buying & -.06 & $-.54^{\text {ns }}$ \\
H1c $\quad$ Ideal self-congruence $\rightarrow$ External trash-talking & -.12 & $-1.09^{\text {ns }}$ \\
H2 $\quad$ Brand attachment $\rightarrow$ Compulsive buying & .43 & $3.48^{* * *}$ \\
H3 $\quad$ Brand attachment $\rightarrow$ External trash-talking & .33 & $2.93^{* *}$ \\
Variance explained $\left(\mathrm{R}^{2}\right)$ & & \\
Brand attachment & & .30 \\
Compulsive buying & & .16 \\
External trash-talking & \multicolumn{2}{c}{.08}
\end{tabular}

Note: $\overline{\mathrm{SPC}}=$ Standardized Path Coefficient; ${ }^{\mathrm{ns}}$ not significant, ${ }^{* * *} p<.01,{ }^{* * *} p<.001$ 